\title{
MANTRA SASAK: KLASIFIKASI, FUNGSI, DAN PENGGUNAANNYA OLEH MASYARAKAT DESA GANGGELANG
}

\author{
SASAK VERBAL-SPELLS (MANTRA): CLASSIFICATION, FUNCTION, \\ AND ITS USAGE BY THE GANGGELANG VILLAGE INHABITANS
}

\author{
${ }^{1}$ Lalu Fakihuddin, ${ }^{2}$ Gita Sarwadi \\ 1,2Universitas Hamzanwadi \\ 1'fakihuddinlalu@yahoo.co.id
}

\begin{abstract}
Abstrak
Tujuan penelitian ini, yaitu (1) mengklasifikan mantra/jejampi Sasak bendasarkan ragam bahasa yang digunakan dan tujuan penggunaannya; dan (2) mendeskripsikan fungsi dan kegunaannya bagi masyarakat Sasak umumnya dan masyarakat Desa Ganggelang, Kabupaten Lombok Utara khususnya. Penelitian ini menggunakan rancangan penelitian kualitatif yang bersifat deskriptif-interpretatif. Data penelitian ini dikumpulkan dengan mewawancarai sejumlah informan dan merekam data berupa mantra-mantra Sasak, tujuan penggunaan, dan fungsi serta kegunaannya oleh masyarakat Sasak. Untuk pengklasifikasian data berdasarkan media bahasa yang digunakan, digunakan bermeneutik. Analisis data mengacu pada model perspektif-konstruktivis, yakni diarahkan oleh intensi, kategori-kategori yang telah ditentukan, dan target hasil yang ingin dicapai. Hasil penelitian ini, yaitu mantra/jejampi Sasak dilihat dari media bahasa yang digunakan, terdiri atas jejampi yang menggunakan bahasa/tulisan Arab, jejampi campuran bahasa Sasak dan diksi Arab, dan jejampi menggunakan bahasa Bali atau disebut puji Bali. Berdasarkan tujuan penggunaannya, mantra Sasak dikelompokkan menjadi mantra dengan tujuan pengobatan, senggeger pemikat hati lawan jenis, mantra penumbuh rasa kasih (seasih-asih), mantra kesaktian, dan mantra penghilang tenaga. Berdasarkan fungsi dam kegunaannya, mantra Sasak memiliki fungsi pengobatan/penolak penyakit, sebagai seasih-asih, sebagai senggeger/sencolet, sebagai media mempermudah proses persalinan, sebagai penolak mantra orang lain (sengkeles), sebagai penolak marabahaya (sepenebeng), sebagai ajian kekebalan, dan sebagai penghilang tenaga.
\end{abstract}

Kata kunci: mantra, jejampi, Sasak, klasifikasi, fungsi.

\begin{abstract}
The purposes of this research are: (1) To classify the Sasak verbal-spells based on the variations of the language being used and the purpose of its implementation; and (2) to describe function and its usage for the Sasak people in general and Ganggelang villagers, North Lombok in particular. This research uses qualitative-research method that both descriptive-interpretative. One of the reasons for choosing such method is because it is compatible with the purpose of this research which is to document and describe the usage of Sasak verbal-spells. The data are collected by interviewing informants and gathering the results of the verbal-spells, its usage and function by the Sasak people. To classify the data based on the language medium, a bermeneutic approach has been employed. The data analysis refers to perspective-constructivist model, that is directed by the intentions, categories that have been determined, and hypotheses that are aimed to be achieved. The result of this research, which is the verbal-spells then analysed based on the language such as Arabic (verbal and written) spells, mixed between Sasak and Arabic spells, and Balinese spells or known as Puji Bali. Based on its purpose of implementation, Sasak verbal-spells are categorised into for healing purposes, Senggeger: a type of
\end{abstract}


voodoo to attract the loved ones, Seasib-asib:to make one falls in love, supernatural power, and draining someone's (physical) energy/power. Based on its function and practical usage, the Sasak verbal-spells have functions as healing/preventing diseases, to Seasib-asihpurposes, to Senggeger/sencoletpurposes, as a medium to ease childbirth processes, to counter other's spells (sengkeles), and to counter possible dangers or destructions (sepenebeng/ajiankekebalan) and to drain someone's energy.

Kata Kunci: verbal-spells, jejampi, sasak, classification, function

\section{PENDAHULUAN}

Sejak beberapa waktu yang lalu sastra lisan termasuk di dalamnya folklor lisan sudah banyak menjadi fokus perhatian para ahli bahasa dan budaya di Indonesia. Hal ini mengindikasikan bahwa sastra lisan (khususnya folklor) memliki daya tarik khusus di kalangan akdemisi. Hal ini setidaknya diungkap oleh (Rafiek 2010: 49) yang menyatakan, "Maraknya penelitian sastra lisan dan sastra Melayu Klasik di Indonesia akhir-akhir ini mengundang gairah (geliat) teori sastra lisan untuk berperan penting. Folklor pun tak luput dari sorotan para peneliti Indonesia. Hal ini menjadi suatu pertanda naiknya pamor mereka dalam kencah akademis."

Maraknya penelitian sastra lisan ini dapat dilihat dari banyaknya hasil kajian akhir-akhir ini. Sekadar contoh penting disajikan beberapa, di antaranya Fungsi dan Makna Tradisi Lisan Genjek Kadong Iseng ( Mantra, I.B.N. dan Sri Widiastuti, I.A.Md. , Jurnal Bakti Saraswa Vol.03 No.02. September 2014 ISSN : 2088-2149); Struktur dan Fungsi Mantra Pengobatan di Desa Kuala Lagan Kecamatan Kuala Jambi Kabupaten Tanjung Jabung Timur Provinsi Jambi (Rizky Novia C.W 1) Maizar Karim2) Eddy Pahar Harahap2); Memburu "Cinta" Dengan Mantra: Analisis Puisi Mantra Orang Jawa Karya Sapardi Djoko Damono Dan Mantra Lisan (Heri Isnaini, Jurnal ilmiah Semantik, STKIP Siliwangi Bandung); Struktur dan Makna Mantra Bekumpang Sastra Lisan Dayak Kantuk (Yuliana Wardani, Totok Priyadi, Henny Sanulita, Pendidikan Bahasa dan Sastra Indoonesia FKIP Untan, Pontianak); dan Unsur-unsur Ekologi dalam Sastra Lisan Mantra Pengobatan Masyarakat Kelurahan Kuranji (Iswadi Bahardur, Suryo Ediyono, Pendidikan Bahasa dan Sastra Indonesia, Pascasarjana UNS). Tentu masih banyak lagi tulisan/kajian yang memfokuskan kajiannya pada Sastra Lisan, secara khusus mantra.

Fakta tersebut menggambarkan, bahwa sastra lama, khususnya folklor lisan menarik untuk dikaji karena beberapa alasan, di antaranya folklor merupakan warisan leluhur; folkor sarat dengan nilai-nilai budaya; dan alasan lainnya yaitu sebagai pelestarian dan penghargaan terhadap nilai-nilai budaya suatu masayrakat tertentu. Masalah ini sejalan dengan pandangan Rafiek (2010:50):

Folklor merupakan warisan turun-temurun yang senantiasa memberikan nilai pendidikan dan nilai budaya bagi generasi muda untuk mempertahankan jati diri daerah dan budayanya. Jati diri dan eksistensi itu menuntut mempertahankan (pemertahanan) dan pelestarian dari generasi muda sekarang untuk lebih memasyarakatkan dan mencintai budaya 
tersebut, alhasil, tentu saja hal itu menuntut kesiapan mereka dalam menghargai dan menghormati budayanya tersebut.

Salah satu bentuk folklor lisan yang merupakan bagian dari sastra lama adalah mantra atau jejampi (sering juga disebut basa beciq) dalam bahasa Sasak. Mantra ini hampir eksis di setiap masayarakat Indonesia, tidak terkecuali masyarakat Sasak di Lombok Nusa Tenggara Barat. Masyarakat Sasak pada umumnya, masyarakat Sasak di pedesaan khususnya, masih banyak memanfaatkan mantra atau jejampi dalam praktek pengobatan tradisional dan masalah-masalah lain yang tekait dengan perdukunan. Kepercayaan terhadap ilmu perdukunan ini, bagi masyarakat tertentu masih bertahan hingga sekarang. Masih banyak anggota masyarakat Sasak, sebelum berobat ke dokter terlebih dahulu berobat ke para dukun atau orang pintar. Sebaliknya, ada juga yang setelah berobat ke dokter namun belum sembuh, selanjutnya berobat ke dukun, bahkan ada yang lebih mengutamakan berobat ke dukun sebelum berobat ke dokter.

Salah satu kelompok masyarakat Sasak yang kaya dengan mantra/jejamp iadalah masyarakat Desa Ganggelang, Kabupaten Lombk Utara, Propvinsi Nusa Tenggara Barat. Bagi masyarakat desa tersebut, praktek pengobatan tradisional dan perdukunan untuk menyelesaikan suatu masalah masih cukup banyak ditemukan.

Masyarakat Sasak umumnya, dan masyarakat Desa Ganggelang khususnya memandang bahwa mantra/jejampi bukanlah bahasa yang tabu dalam kehidupan mereka, bahkan mereka meyakini bahwa mantra bisa menyelamatkan jiwa mereka dari berbagai gangguan makhluk halus dan manusia yang ingin berbuat jahat. Masyarakat Sasak umumnya mengenal beberapa jenis mantra, di antaranya jejampi, puji, asih-seasih, senggeger, sibir, dan senggedik.

Berdasarkan informasi dari beberapa informan dan berdasarkan pengamatan awal, masyarakat Ganggelang sering menggunakan mantra/jejempi. Kalau diteliti lebih jauh, masyarakat Desa Genggelang sering menggunakannya pada acara atau kegiatan-kegiatan tertentu, seperti pengobatan, pembuat kekuatan, penumbuh rasa cinta dan kasih, pemunculan penyakit, dan pemicu kebencian, dan lain-lain.

Penelitian secara khusus puisi-puisi lama masyarakat Sasak, khususnya mantra/jejampi sangat diperlukan karena mantra merupakan bagian kebudayaan lokal yang diwaiskan turuntemurun dan memiliki fungsi sebagai salah satu bentuk kearifan lokal Sasak. Sebagai kearifan lokal, tidak diharapkan hilang begitu saja tertelan zaman. Oleh karena itu, perlu diinventarisasi, didokumentasi, dan dideskripsi fungsi dan kegunaannya agar generasi mendatang lebih memahami budaya lokal mereka. Terkait hal ini perlu dicermati pernyataan berikut ini.

Puisi rakyat Sasak merupakan salah satu bentuk kebudayaan daerah yang tumbuh dan berkembang di tengah-tengah masyarakat Sasak dan diwariskan dengan cara turun-temurun secara lisan sebagai milik bersama. Puisi rakyat Sasak memiliki fungsi dalam kehidupan kelompok atau masyarakat yang memilikinya. Dan tentunya tidak mustahil pada suatu saat puisi rakyat Sasak ini akan hilang tanpa bekas. Oleh karena itu, perlu dilakukan penelitian dan pendeskrifsian terhadap puisi rakyat Sasak agar pewarisannya pada generasi selanjutnya akan bisa lebih terjamin.(Dekdikbud, 1986: 1). 
Alasan-alasan yang telah disajikan sebelumya dan kutipan-kutipan yang memperkuat alasan tersebut menjadikan peneliti memandang perlu melakukan pengkajian secara khusus terhadap salah satu jenis puisi lama Sasak, yakni mantra/jejampi. Alasan-alasan lain yang membuat masalah ini perlu diteliti, yaitu belum tuntasnya terdokumentasi puisi-puisi mantra/jejampi Sasak secara rapi dan khuus. Dengan ditelitinya puisi-puisi lama Sasak tersebut, masyarakat pemiliknya (generasi mendatang) dapat mempelajarinya pada waktu-waktu mendatang, baik dalam kaitan akademik maupun nonakademik.

Menurut informan, masih banyak masyarakat Desa Genggelang, Kabupaten Lombok Utara memiliki puisi rakyat Sasak. Hal ini didukung oleh kebiasaan mayarakat menggunakannya pada acara-acara adat dan acara pengobatan tradisional. Berangkat dari persoalan tersebut, inventarisasi, dokumentasi, dan penelaahan lebih lanjut sangat diperlkan demi terjaganya asset kebudayaan dan kearifan lokal masyarakat Sasak. Jika tidak segera dilakukan, dalam beberapa waktu ke depan, bisa dipastikan aset loksl ysng berharga ini akan punah

Penelitian ini difokuskan pada puisi lama masyarakat Sasak yang berbentuk mantra/jejampi yang eksis dalam kehidupan masyarakat di Desa Genggelang, Kabupaten Lombok Utara. Subvariabel kajian, yaitu pengklasifikasian, pendeskripsian fungsi/kegunaannya oleh masyarakat Desa Ganggelang. Data mantra diambil dari dua dusun, yakni Dusun Paoq Rampek dan Dusun Penjor. Mengacu kepada latar belakang dan fokus masalah yang telah disajikan, tulisan ini akan menyajkan: (1) pengklasifikasian mantra/jejampi Sasak bendasarkan ragam bahasa yang digunakan; (2) pengklasifikasi mantra Sasak berdasarkan tujuan; dan (3) pendeskripsian fungsi dan kegunaannya bagi masyarakat Sasak umumnya dan masyarakat Desa Ganggelang, Kabupaten Lombok Utara khususnya. Adapun tujuan penelitian ini, yaitu: (1) untuk mengklasifikasikan bentuk mantra/jejampi Sasak berdasarkan ragam bahasa yang digunakan; (2) mengklasifikasi jejampi Sasak berdasarkan tujuan penggunaannya; dan (3) mendeskipsikan fungsi dan kegunaannya oleh masyarakat Sasak, khususnya masyarakat Ganggelang, Kabupaten Lombok Utara.

Untuk menunjang analisis dan pemahaman terhadap topik yang dibahas, digunakan tiga teori, yaitu (1) Sastra lisan, (2) puisi rakyat, dan (3) mantra.

Sebelum disajikan secara khusus kajian teori tentang sastra lisan, ada baiknya terlebih disajikan secara ringkas kajian teori tentang sastra ( lisan). Ada banyak variasi batasan sastra (sastra lisan) oleh para ahli. Untuk kepentingan kajian ini, penulis menyajikan beberapa di antaranya. Semi (1993:3) menjelaskan eksistensi sastra lisan di Indonesia:

Sastra lisan yang terdapat pada masyarakat suku bangsa di Indonesia telah lama ada, bahkan setelah tradisi tulis berkembang, sastra lisan masih kita jumpai. Baik dari segi kualitas maupun dari segi kuantitas sastra lisan di Indonesia luar biasa kayanya dan luar biasa ragamnya. Melalui sastra lisan, masyarakat dengan kreativitas yang tinggi menyatakan diri dengan menggunakan bahasa yang artistic . Bahkan pada saat sekarang pun, kita masih menjumpai kehidupan sastra lisan terutama yang digelarkan dalam upacara-upacara adat. 
Untuk melihat luasnya cakupan dalam pengertian sastra lisan menarik disajikan penjelasan panjang terkait sastra lisan sebagai berikut.

Terdapat varietas yang sangat mengejutkan dari sastra lisan yang bertahan hidup di antara orang-orang praaksara, dan sebagaimana kata-kata tertulis muncul dalam sejarah, menunjukkan bahwa semua genre penting sastra yang muncul pada awal masyarakat beradab adalah: epos heroik, nyanyian pujaan untuk pendeta dan raja, cerita misteri dan supernatural, lirik cinta, nyanyian pribadi hasil meditasi, kisah cinta, kisah petualangan dan heroisme rakyat jelata, yang berbeda dari epos heroik kelas atas, satir, satir pertempuran, balada, dogeng tragedi rakyat dan pembunuhan, cerita rakyat, fabel, teka-teki, pepatah, falsafah hidup, himne, mantra-mantra, nyanyian misteri para pendeta, dan mitologi (Rafiek 2010: 54).

Sastra lisan lebih dulu muncul dan berkembang di masyarakat dari pada sastra tulis. Shipley (1962) menjelaskan, sastra lisan itu mencakup cerita rakyat, teka-teki, pribahasa, kepercayaan, pepatah, legenda, mite, dan certia lisan rakyat. Secara lebih rinci sastra lisan dan cirri-cirinya dekemukakan sebgai berikut.

Sastra lisan adalah karya yang penyebarannya disampaiakn dari mulut ke mulut secara turun-temurun. Ciri-ciri sastra lisan itu adalah (1) lahir dari masyarakat yang polos, belum melek huruf, dan bersifat tradisional; (2) menggambarkan budaya milik kolektif tertentu, yang tak jelas siapa penciptantya; (3) lebih menekankan aspek khayalan, ada sindiran, jenaka, dan pesan pendidik; dan (4) sering melukiskan tradisi kolektif tertentu. (Rafiek 2010: 53).

Sastra lisan salah satunya muncul dalam bentuk puisi rakyat. Puisi rakyat, seperti syair, mantra, bidal, pantun dan gurindam identik dengan ciri belum terpengaruh oleh Barat (Surendra, 1995: 226). Salah satu puisi rakyat yang paling mula-mula ada adalah mantra dan bidal (Badudu, 1982). Badudu (1982: 6) menjelaskan mantra sebagai kata-kata yang mengandung hikmat dan kekuatan gaib. Kata-kata ini biasanya hanya diucapkan oleh orangorang tertentu seperti dukun atau pawang. Tidak semua orang boleh mengucapkan mantra karena kesalahan dalam mengucapkannya menurut kepercayaan dapat mendatangkan bahaya". Mantra adalah salah satu bentuk puisi yang dianggap mempunyai kekuatan adikodrati; digunakan oleh dalang sebelum memulai pementasan wayang (Suhendra 1995: 174).

Mantra dapat dipakai untuk pengobatan, kekebalan, senggeger, dan pembuat penyakit, dengan demikian, berdasarkan kegunaannya basa beciq/mantra dapat dibagi menjadi empat, yaitu: jejampi, puji, asih-seasih, senggegger, begiq, dan senggedik (Dekdikbud 1986: 15 ) Mantra bisa diartikan sebagai susunan kata yang berunsur puisi (seperti rima dan irama) yang dianggap mengandung kekuatan gaib, bisanya diucapkan oleh dukun atau pawang untuk menandingi kekuatan gaib yang lain. Mantra terdiri atas beberapa jenis, misalnya berdasarkan tujuan penggunaannya dikenal mantra pengobatan, mantra perlindungan diri, mantra penumbuh rasa 
kasih, mantra untuk tujuan memulai upacara adat, dan lain-lain. Dari segi bentuk, mantra sebenarnya lebih sesuai digolongkan ke dalam bentuk puisi bebas, yang tidak terlalu terikat pada aspek baris, rima dan jumlah kata dalam setiap baris. Dari segi bahasa, mantra bisaanya menggunakan bahasa khusus yang sukar dipahami. Adakalanya, dukun atau pawang sendiri tidak memahami arti sebenarnya mantra yang ia baca; ia hanya memahami kapan mantra tersebut dibaca dan apa tujuannya. Dari segi penggunaan, mantra sangat eksklusif, tidak boleh dituturkan sembarangan, karena bacaannya dianggapa keramat dan tabu (Admin 2008).

\section{METODE PENELITIAN}

Penelitian ini menggunakan rancangan penelitian kualitatif yang bersifat deskriptif interpretatif. Alasan pemilihan desain ini antara lain karena penelitian ini bertujuan untuk mendokumentasikan dan mendeskrpsikan mantra Sasak yang digunakan oleh masyarakat Sasak di Desa Ganggelang, Kabupaten Lombok Utara. Salah satu ciri penelitian deskriptif, yaitu must be based upon what people say (Nida, 1962 dalam Purba, dkk. 1994). Dikatakan bersifat interpretatif karena proses penelitian didasarkan pada signikansi-interpretatif, dan peneliti sendiri sebagi instrumen kunci (buman instrument). (Fakihuddin, 2015; Fakihuddin, 2018).

Pengumpulan data penelitian ini dilakukan dengan mewawancarai sejumlah informan (8 Orang) dan merekam data berupa mantra-mantra Sasak, tujuan penggunaan, dan fungsi serta kegunaannya oleh masyarakat Ganggelang menggunakan smart phone. Wawancara juga digunakan untuk mengumpulkan data terkait dengan makna social mantra Sasak. Pengumpulan data dilakukan secara berulang-ulang sampai peneliti merasa bahwa data yang diperlukan telah cukup. Untuk melengkapi data yang terkumpul, dilakukan juga observasi lasngsung ketika para informan melakukan praktek pembacaan mantra pada kegiatan-kegiatan tertentu.

Untuk kebutuhan pengklasifikasian data berdasarkan media bahasa yang digunakan, digunakan hermeneutik, yakni suatu metode yang berusaha menafsirkan makna secara mendalam dari sebuah teks (Fakihuddin 2013). Dalam kajian dengan penelitian ini teks yang dimaksud adalah mantra Sasak yang telah terdokumentasikan. Pendekatan ini dipilih karena tugas pokok hermeneutik adalah menafsirkan sebuah teks sehingga dimengerti banyak orang pada zaman yang berbeda( Adaptasi dari Hidayat, 1996; Aminudidn, 1990 dalam Fakihuddin 2013). Analisis data dalam penelitian ini mengikuti tahapan-tahapan: pengumpulan data, penyeleksian data, pengklasifikasian data, penganalisisan dan penginterpretasian data.

\section{HASIL DAN PEMBAHASAN}

\section{Mantra Berdasarkan Bahasa yang Digunakan}

\section{a. Jejampi Bahasa Arab}

Jejampi ini menggunakan bahasa Arab secara keseluruhan.

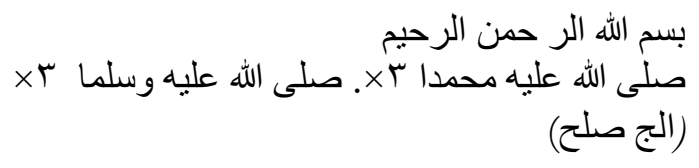




\section{b. Jejampi Bahasa Sasak bercampur diksi Arab}

Meskipun menggunkan bahasa Sasak, dalam diksi tertentu muncul diksi yang berasal dari bahasa Arab, seperti kata alif, fateha, dan lain-lain.

Dik ba, ku alif

Endel diman kaman fateha

Ku angansalin penyakit agung okon aku

Berkat lailahaillalloh. Muhammadurrasululloh.

\section{c. Bahasa Puji Bali}

Musa kali Musa. Musa kalimulloh

Ija aran mek Pengulah jari tau Bali. dan

Wot, wot, wot Isa Musa

Bunut sungsang maran alin-alin batu depak peseng erahan ida.

\section{Mantra Berdasarkan Tujuan Penggunaan}

Berdasarkan tujuan penggunaannya, mantra Sasak dapat diklasifokasikan sebagai berikut.

\section{a. Untuk Pengobatan}

Tujuan dan kegunaan pembacaan mantra berikut adalah sebagai obat sakit perut (anak)

\begin{tabular}{|l|l|}
\hline \multicolumn{1}{|c|}{ Mantra/Jejampi } & \multicolumn{1}{|c|}{ Terjemahan } \\
\hline Tangon goro, tangon ngorak & 'Antap kering, antap muda \\
Tawar-tawar mandi & Tawar-tawar. Sakti mantra saya \\
munterangku sinq ngowat & untuk mengobati sakit perut anak \\
sakit tian bebeaq deq tao & yang tidak bisa memberitahu \\
membarak. Berkat & sakitnya' \\
lailahaillallah (H.Mahyudin). & \\
\hline
\end{tabular}

Obat sakit kepala

\begin{tabular}{|l|l|}
\hline \multicolumn{1}{|c|}{ Mantra } & \multicolumn{1}{|c|}{ Terjemahan } \\
\hline Payungku, payung Allah & 'Payung saya, payung Allah. Saya \\
Kujampi sakit ulu, Bukaq ger & obati sakit kepala. Terbuka supaya \\
mapet. Mandi munterangku & tertutup sakti \\
Lailahaillalloh (Papuq Sundip). & mantra saya' \\
\hline
\end{tabular}

b. Untuk Menarik Perhatian Lawan Jenis/Sebagai senggeger

Senggeger ini masih dikelompokkan lagi sebagai

\section{1) Senggeger Sencolet}

Tujuh ling tikar, tujub ling maglap

Ingat dik Jibril Allah tunggal

Maring gumi Allah eka

Mandi munterangku angadok ujud Malaekat Jibril ujud pegat mara. Berkat, Lailahaillallah Mubammadurasulullah 
'Tujuh kata tikar, tujuh kata bantal

Ingat kamu Jibril Allah tunggal

Penguasa alam Allah satu

Sakti mantra saya memakai penampakan Malaikat Jibril Penampakan putus pekerjaan.'

\section{2) Senggeger Jalan}

'Sung gumi, sung langit, sung bintang

Mandi munterangku cobak cahaya Anak. Adam okon rokok.

Penguasa bumi, penguasa langit, penguasa bintang. Sakti mantra saya menggunakan cahaya anak Adam lewat rokok.'

\section{3) Senggeger Makanan}

Bismillah

Puntik susu, puntuk tanak

Segenter paku-paki susungku kuning dadang

Dadangku kuning

Mapanku ngadokang senggeger jalan puntik

Ingat puntik bauwang musuh dik aran...(orang yang dituju)

Berkat. Lailahaillallah Muhammadurasululloh. (Mamiq Udik)

'Dengan nama Allah

Pisang susu, pisang tanah segenter

Paku-paki susungku kuning dadang

Dada saya kuning

'Saya menggunakan senggeger lewat pisang

Ingat pisang luluhkan musuh kamu yang bernama....'

(orang yang dituju).

\section{c. Untuk Memunculkan rasa sayang/Sebagai seasih-asih}

Asih-seasih adalah mantra yang digunakan untuk menaruh rasa kasih sayang. Ini dikelompokkan menjadi:

\section{1) Asih-Seasih Bali}

Wot, wot, wot Isa Musa

Bunut sungsng waringin

Sungsang maran alin-alin batu depak.

Peseng erahan ida.

Teka-teki, teka-teki, teka-teki

Sir setaki aku duduk. Mengaibkean

sabadat tau Bali ngamulia di laut putih.

\section{2) Asih-Seasih Sasak}


Bumi sepi Langit sepi

Seapuannya pada milu menangis

Daud teka Daud teka inang teka geger

Mandi munterangku angadokang asih-asih sepujaan Nabi Daud. Berkat Lailahaillallah, Muhammadurasululloh.

'Alam sepi langit sepi

Semuanya ikut menagis teka inang teka geger

Sakti mantra saya menggunakan asih-seasih kebanggaan Nabi Daud'

\section{d. Untuk Tujuan Kesaktian}

Puji adalah sejenis mantra yang digunakan oleh orang Sasak untuk tujuan kekebalan. Puji Sasak ini masih dibagi lagi menjadi

\section{Puji Sasak}

\section{Sengkales}

Eh memeh sensonan dak dadang

Kalang tangkis kiri kanan

Kalang tangkis julu mudi

Kalang tangkis bao bawaq

Nabi Mubammad nurunan Jibril

Mandi munterangku angadok sentuluk sengkales.

Berkat lailabaillallah, Muhammadurasululloh.

'Wahai memeh sensonan dak dadang

Menajaga tangkis kiri-kanan

Menjaga tangkis depan-belakang

Menjaga tangkis atas-bawah

Nabi Muhammad lebih tinggi dari Jibril

Sakti mantra saya menggunakan sentulaq sengkales.'

\section{Sepenebeng}

Sepenebeng bumi langit, Ku nebeng anak. Nabi Adam kipet-kapat sepenebeng Nabi Adam Berkat lailabaillallah, Mubammadurasululloh. (Mamiq Siarna).

'Sepenjaga bumi langit

Saya jaga anak Nabi Adam tertutup rapat sepeneng Nabi Adam Berkat lailahaillah, Muhammadurasululloh.'

\section{Senteguh atau sengkebal}

Oyot-oyot koloh bebandan

Payung ijo payung koe

Ya sengkolot ya badan isiq ito ya isiq ite

Berkat Lailahaillallah, Muhammadurasululloh. 


\section{e. Untuk Menghilangkan Tenaga/Begik atau Sihir}

Ada dua jenis mantra sihir, yaitu sebagai sihir itu sendiri dan sebagai mantra pengobatan. Adapun bentuk dari mantra sihir ini banyak jenisnya, yakni: Selempak Lembain, Sokeq, Banggeruk, Perut Buncit, Serua Rasa. Akan tetapi yang peneliti dapatkan hanya penghilang balung atau tenaga dan sentulak selempak lembain saja.

\section{1) Penghilang tenaga}

Hinur janur, bilang walung

Hiku rumpub gedokan ana

Ku ngadokang sekebat lindur balik sekali

Berkat lailahaillallah, Muhammadurasululloh.

\section{2) Sentulak selempak lembain}

Ingsul wih sita luih malih

angsal sita Malaekat Kiraman leq kananku

Malaekat Mingkail leq kiringku

Malaekat Jibril leq mudingku

bae Malaekat Jibril silaq de kaji

sentulakang ate angen setan Iblis yang tertutup

ate angen, wong sekabeh okon aku.

Berkat lailahaillallah, Mubammadurasululloh. (Amiq Dip)

'Ingsul wih sita luih malih

Asalkan kalian Malaikat Kiraman di kanan saya

Malaikat Mingkail di kiri saya

Malaikat Jibril di belakang saya

Wahai Malaikat Jibril silahkan engkau

Kemabalikan dan jaga niat setan Iblis yang tertutup niat pada kami semuanya pada saya.'

\section{3) Senggedik}

Senggedik atau sengerik istilah orang sasak, jika seseorang yang terkena mantra senggedik ini akan putus cinta kasihnya.

Puji Cerai

Eh runtu-rante, buta ate buta mata

Ku simpat gedung Allah ku simpat masalah

Ku simpat si kunci kuri gedung Allah

Ku simpat masalah sekunci gedung Mubammad

Ingetku angadokang semungkem gedung Mubammad.

Berkat lailahaillallah, Muhammadurasululloh.

'Wahai runtu-rante, tertutup hati buta mata 
Saya tutup gedung Allah saya tutup masalah

Saya tutup sekunci kuri gedung Allah

Saya tutup masalah sekunci gedung Muhammad

Ingat saya menggunakan semungkem gedung Muhammad.'

\section{Fungsi dan Keguaan Matra/Jejampi bagi Masyarakat Ganggelang}

Berdasarkan fungsi dan kegunaannya, mantra/jejampi Sasak dapat dikelomokkan menjadi:

\section{a. Sebagai penolak penyakit (Pengobatan)}

Mantra berikut ini biasa digunakan para dukun untuk pengobatan. Mantra berikut digunakan untuk mengobati anak-anak yang menderita sakit perut.

Tangon goro, tangon ngorak

Tawar-tawar mandi munterangku

sinq ngowat sakit tian bebeaq deq tao membarak.

Berkat lailahaillallah

Dik ba, ku alif

Endel diman kanan fateha

Ku ngansalin penyakit agung okon aku.

Berkat Lailahailallah.

Jejampi sakit kepala

Payungku payung Allah

Ku jampi sakit ulu

Bukaq ger mapet. Mandi munterangku

berkat lailahailallah.'

\section{b. Sebagai Asih-seasih (Mendatangkan Simpati)}

Mantra asib-seasib ini biasa digunakan agar seseorang menaruh rasa kasih sayang, mendatangkan simpati orang pada hal-hal tertentu. Misalnya, mantra asib-seasib jejuluk Nabi Daud digunakan untuk menjadkan rasa simpatiseseorang kepada yang diniatkan. Bacaan asihseasih Sasak yang bernama jejuluq Nabi Dawud ini cukup sederhana, tetapi memiliki daya ampuh yang luar biasa (menurut informan)., bacaannya adalah:

Asib-seasib Nabi Dand

Bumi sepi langit sepi

Selapuannya pada milu menagis

Dand teka dand

Teka inang teka geger. Mandi munterangku ngadokang asih-seasib sepujaan Nabi daud. Berkat lailahailallah.

Asib-seasih lainnya, yaitu Asih-Seasih Bali, contoh mantranya: 
Wot, wot, wot Isa Musa

Bunut sungsng waringin

Sungsang maran alin-alin batu depak

Peseng erahan ida.

Teka-teki, teka-teki, teka-teki

Sir setaki aku duduk. Mengaibkan sabadat tau Bali ngamulia di laut putih.

\section{c. Sebagai Senggeger}

Senggeger adalah salah satu mantra Sasak yang dikenal dikalangan masyarakat sasak, khususnya kaum muda, baik pria maupun wanita, bahkan kaum tua pun bisa menggunakan senggeger. Mantra senggeger berfungsi sebagai pemikat agar pemuda/pemudi yang menggunakan mantra ini dicintai atau disayangi oleh lawan jenis yang dituju. Mantra ini dibagi menjadi senggeger sencolet, sengeger jalan, dan senggeger makanan. Berikut masing-masing contohnya.

1) Senggeger Sencolet

Tujuh ling tikar, tujub ling maglap

Ingat dik Jibril Allah tunggal

Maring gumi Allab eka

Mandi munterangku angadok ujud Malaekat Jibril ujud pegat mara. Berkat, Lailahaillallah

Muhammadurasululloh.

\section{Mantra senggeger sencolet Ujud Jibril.}

Tujub ling tiker, tujub ling maglap

Inget dik jibril Allah tunggal

Maring gumi Allah eka

Mandi munterangku angadok ujud malaekat jibril ujud pegat mara. Berkat lailahailallah.

\section{2) Senggeger Jalan}

Sung gumi, sung langit, sung bintang

Mandi munterangku cobak cahaya Anak. Adam okon rokok.

\section{3) Senggeger Makanan}

\section{Bismillab}

Puntik susu, puntuk tanak

Segenter paku-paki susungku kuning dadang

Dadangku kuning

Mapanku ngadokang senggeger jalan puntik.

Ingat puntik bauwang musub dik aran...(orang yang dituju)

Berkat. Lailahaillallah Mubammadurasululloh. (Mamiq Udik)

\section{d. Sebagai Sarana Mempermudah Persalinan}

$$
\text { ـ صلى الله عليه محمد ب×. صلى الله عليه وسلم س }
$$


Kalimat tersebut merupakan sholawat kepada Nabi Muhammad, SAW. Mantra Shalawat ini diyakini mampu memudahkan segala urusan, termasuk urusan dalam persalinan/melahirkan. Menurut informan, kalimat tersebut pernah dibaca oleh Malaikat Jibril A.S. ketika Siti Aminah hendak melahirkan Nabi Muhammad SAW. Berkat bacaan Malikat Jibril itu, siti aminah dengan mudah melahirkan Nabi Muhammad SAW.Itulah landasan "orang Sasak" mengambil shalawat itu sebagai mantra/doa persalinan.

\section{e. Sebagai Begik}

Begik .dalah kebalikan dari senggeger dan tergolong dalam ilmu hitam. Begik digunakan untuk membuat orang yang di-begik sakit. Penyakit-penyakit yang bisa ditimbulkan oleh begik, misalnya perut membengkak, mulut moncong, sokoq, selempaq lembain, dan muntah darah. Contohnya mantra yang tergolong begik ini adalah mantra sentulaq selempak lembain. Contohnya sebagai berikut.

Ingsul wih sita luih-malih angsa sita

Malaekat Kiraman lek kananku

Malaekat Katibin lek kiringku

Malaekat Mingkail lek julungku

Malaekat Jibril lek mudingku

Hae Malaekat Jibril silaq de kaji

Sentulakang ate angen setan iblis yang tertutup ate angen wong sekabeh okon aku. Berkat lailahailallah.

\section{f. Sebagai Puji atau Kesaktian}

Puji adalah jenis mantra yang digunakan oleh orang Sasak (Ganggelang) untuk tujuan kekebalan. Mereka menyakini, bahwa dengan membaca mantra ini seseorang akan memiliki kekuatan ekstra. Sejarah awal penggunaan mantra ini, (menurut informan)adalah ketika orang Sasak berperang melawan Belanda, Jepang, dan Bali. Puni ini ada beberapa jenis, diantaranya Puji Sasak (sengkales, sepenebeng, dan sengkebal). Berikut contoh-c0ntoh mantranya.

\section{Sengkales}

Eh memeh sensonan dak dadang

Kalang tangkis kiri kanan

Kalang tangkis julu mudi

Kalang tangkis bao bawaq

Nabi Muhammad nurunan Jibril

Mandi munterangku angadok sentuluk sengkales.

Berkat lailahaillallah, Mubammadurasululloh. 


\title{
Sepenebeng
}

Sepenebeng bumi langit, Ku nebeng anak Nabi Adam kipet-kapat sepenebeng Nabi Adam Berkat lailahaillallah, Muhammadurasululloh.

\section{Senteguh atau sengkebal}

Oyot-oyot koloh bebandan

Payung ijo payung koe

Ya sengkolot ya badan isiq ito ya isiq ite

Berkat.Lailahaillallah, Mubammadurasululloh.

\section{g. Sebagai Begik atau Sihir}

Ada dua jenis mantra sihir dan mantra pengobatannya. Adapun bentuk dari mantra sihir ini banyak jenisnya, yakni: Selempak Lembain, Sokeq, Banggeruk, Perut Buncit, Serua Rasa. Akan tetapi, yang diperoleh hanya mantra penghilang balung atau penghilang tenaga dan sentulak selempak lembain saja.

\section{Penghilang balung/tenaga}

Hinur janur, bilang walung

Hiku rumpub gedokan ana

Ku ngadokang sekebat lindur balik sekali

Berkat lailahaillallah, Mubammadurasululloh.

\section{Sentulak selempak lembain}

\author{
Ingsul wih sita luih malih \\ angsal sita Malaekat Kiraman leq kananku \\ Malaekat Mingkail leq kiringku \\ Malaekat Jibril leq mudingkeu \\ hae Malaekat Jibril silaq de kaji \\ sentulakang ate angen setan Iblis yang tertutup \\ ate angen, wong sekabeb okon aku. \\ Berkat lailahaillallah, Mubammadurasululloh.
}

\section{h. Sebagai Senggedik}

Senggedik atau sengerik istilah orang Sasak difungsikan sebagai media penghilang hilang cinta atau rasa kasih saying seseorang. Jika seseorang telah terkena senggedik, ia akan merasa muak atau tidak suka kepada seseorang/lawan jenisnya. Senggedik ini terdiri atas beberapa macam. Salah satu contohnya adalah senggedik puji cerai sebagai berikut.

\section{Puji Cerai}

Eh runtu-rante, buta ate buta mata

Ku simpat gedung Allah ku simpat masalah

Ku simpat si kunci kuri gedung Allab

Ku simpat masalah sekunci gedung Mubammad 


Ingetku angadokang semungkem gedung Mubammad. Berkat lailahaillallah,

Muhammadurasululloh. (Mamiq Zul)

\section{i. Sebagai Pemikat Hati Perempuan/Senggeger}

Mantra Sasak juga digunakan sebagai pemikat hati seseorang (prempuan). Beberapa mantra yang difungsikan sebagai pemikat hati ini adalah mantra cahaya Adam dan mantra puntik susu. Sahadat Bali, mantra sepujaan Nabi Dawud, Mantra-mantra ini berfungsi sebagai pemikat hati seorang perempuan agar tertarik kepada lelaki yang mengharapkan cintanya. Media yang digunakan di antaranya, asap rokok, makanan, minuman, dll.

\section{SIMPULAN}

Bedasarkan pembahasan yang telah disajiakan dapat dasimpulkan, bahwa mantra Sasak atau dikenal dengan istilah Jejampi/basa beciq dilihat dari media bahasa yang digunakan, terdiri atas jejampi yang menggunakan bahasa Arab, jejampi yang menggunkan campuran bahasa Sasak dan diksi Arab, dan jejampi menggunakan bahasa Bali atau disebut puji Bali.

Berdasarkan tujuan penggunaannya, mantra Sasak dikelompokkan menjadi: mantra pengobatan, mantra senggeger/pemikat hati lawan jenis, mantra penumbuh rasa kasih dan sayang (seasih-asih), mantra kesaktian (puji Sasak, sengkeles, sengkebal, dll.), dan mantra penghilang tenaga (senggediq, sihir, sentulah selampak lembain, dll.) Berdasarkan fungsi dam kegunaannya, mantra Sasak memiliki fungsi: pengobatan/penolak penyakit; sebagai seasih-asih atau mendatangkan rasa sayang atau simpati dari oaring lain; sebagai senggeger/sencolet; sebagai media mempermudah proses persalinan; sebagai penahan/penolak mantra orang lain (sengkeles); Kegunaan lainnya, yaitu menghindarkan seseorang dari mara bahaya ketika bepergian (Mantra sepenebeng), sebagai ajian kekebalan (Mantra sengkebal), sebagai penghilang tenaga (Mantra penghilang tenag). Fungsinya/kegunaan lainnya, yaitu untuk menghilangkan tenaga/kekuatan lawan, sebagai pengobatan Mantra selempak lembain); sebagai pemisah hubungan suami-istri ( Mantra puji cerai).Yang termasuk ke dalam kelompok ini, yaitu mantra Malaikat Harut.

Mantra sebagai salah satu jenis sastra lisan perlu diinventarisasi mengingat mantra sebagai salah satu aset budaya daerah yang perlu dikenal oleh generasi berikutnya. Mengingat penelitian ini masih bersifat awal/umum, perlu dilakukan penelitian secara lebih khusus dan mendalam untuk masing-masing jenis mantra Sasak. Hal ini penting sebagai upaya melestarikan mantra sebagai salah satu kearifan lokal Sasak, khususnya yang berfungsi sebagai pengobatan. 


\section{DAFTAR PUSTAKA}

Admin. "Sastra Lisan". http://Melayuonline.Com (19 Nov 2008).

Alisjahbana, St. Takdir. 2008. Puisi Lama. Jakarta: PT. Dian Rakyat

Alwi, Hasan. 2005. Kamus Besar Bahasa Indonesia Cetakan keempat. Jakarta: Balai Pustaka

Badudu, J.S. 1983. Sari Kesusastraan Indonesia 2. Bandung: Pustaka Prima

Fakihuddin Lalu. 2015. "Eksistensi Masalah Supranatural dalam Folklor Lisa Sasak: Suatu Kajian Tematis terhadap Cerita Rakyat Sasak yang Telah Didokumentasikan. “ (Jurnal Mabasan Volume 9, No.2, Juli-Desember 2015)

Mantra, I.B.N. dan Sri Widiastuti, I.A.Md. , Jurnal Bakti Saraswa Vol.03 No.02. September 2014 ISSN : 2088-2149)

Purba, Th.T. dkk. Morfologi Bahasa Dani Barat. Direktorat Pembinaan Penelitian dan Pengabdian Pada Masyarakat Doirektorat Jenderal Pendidikan Tinggi, Departemen Pendidikan dan Kebudayaan.

Depdikbud. 1986. Sastra Lisan Sasak. Rawamangun: Pusat Pembinaan dan Pengembangan Bahasa

Rahmanto, B. 1993. Metode Pengajaran Sastra. Yogyakarta: Kanisius

Rafiek, M. 2010. Teori sastra: Kajian Teori Dan Tematik. Bandung: PT Rafika Aditama

Rizky Novia C.W dkk. Fungsi "Mantra Pengobatan Di Desa Kuala Lagan Kecamatan Kuala Jambi Kabupaten Tanjung Jabung Timur Provinsi Jambi” . Program Studi Sastra Indonesia FIB Universitas Jambi

Semi, Atar. 1993. Metode Penelitian Sastra. Bandung: Penerbit Angkasa.

Shipley, J.T. 1962. Dictionary of World Literatur. Littlefield, Adams \& Co Patterson, New Jersy.

Sudjiman, Panuti. 1990. Kamus Istilah Sastra.Jakarta: UI-PRESS.

Suhendra, Yusuf 1995. Leksikon Sastra. Bandung: Mandar Maju 